\title{
COMO SOBREVIVER EM UM AMBIENTE DE FINANCIAMENTO INSTÁVEL? GESTÃO DE RECURSOS EM ORGANIZAÇÕES EMPREENDEDORAS DO TERCEIRO SETOR QUE ATUAM COM O ESPORTE
}

DOI:1014211/regepe.v5i1.309

Artigo recebido em: 02/09/2015

Artigo aprovado em: 03/03/2016

Ana Lúcia Castilho da Mota - Universidade Nove de Julho - UNINOVE' Vânia Maria Jorge Nassif - Universidade Nove de Julho - UNINOVE ${ }^{2}$

Resumo: Esta pesquisa tem por objetivo identificar quais são as estratégias, relacionadas à gestão de recursos utilizadas pelas organizações do terceiro setor (OTS) que atuam com o esporte educacional e de participação visando à continuidade de seus projetos e sua sobrevivência. O método adotado foi 0 qualitativo e está baseado na perspectiva fenomenológica, visto que retrata a realidade a partir das experiências subjetivas dos participantes da pesquisa. Para tal, a entrevista foi o instrumento utilizado para coletar os dados. Fizeram parte dessa pesquisa quatro fundadores e sete coordenadores ou diretores de organizações renomadas no Brasil, totalizando onze entrevistas. Os dados foram categorizados à luz de Flores (1999) e o recurso utilizado para auxílio da organização das categorias foi o software Atlas ti, evidenciando duas categorias: Sustentabilidade/Sobrevivência e Gestão Organizacional. Observou-se pelos resultados que socializar experiências de captação e mobilização de recursos pode contribuir para o avanço da sustentação das organizações. A dependência de financiamento é apontada como uma preocupação e um desafio para a sobrevivência das OTS, pela pouca flexibilidade na mobilização de recursos, gerando insegurança para a execução de projetos de médio e logo prazos. A estratégia que essas Organizações vêm buscando para minorar esses problemas é o fortalecimento da instituição por meio de novas parcerias e da articulação em rede visando à construção de políticas públicas para atender as necessidades da população no que tange ao acesso à prática de esportes e também que atendam às especificidades do setor.

Palavras-chave: Estratégia; Gestão de Recursos; Organizações do Terceiro Setor; Sobrevivência; Gestão Social.

\footnotetext{
${ }^{1}$ Endereço:. E-mail:ana@anamota.com.br

2 E-mail: vania.nassif@gmail.com
}

MOTA, A. L. C.; NASSIF, V. M. J. Como sobreviver em um ambiente de financiamento instável? Gestão de recursos em organizações empreendedoras do terceiro setor que atuam com o esporte. Revista de Empreendedorismo e Gestão de Pequenas Empresas, v.5, n.1, 2016. 


\title{
HOW TO SURVIVE IN A FUNDING UNSTABLE ENVIRONMENT? RESOURCE MANAGEMENT OF ENTREPRENEURIAL ORGANIZATIONS OF THIRD SECTOR ACTING TO SPORT
}

\begin{abstract}
This research aims to identify which strategies are related to the management of resources used by third sector organizations (OTS) that work with the educational sports and participation aimed at continuity of their projects and their survival. The method adopted was the qualitative and is based on the phenomenological perspective, as it portrays the reality from the subjective experiences of research participants. To this end, the interview was the instrument used to collect the data. Four founding and seven coordinators or directors of renowned organizations in Brazil were part of this research, totaling eleven interviews. The data were categorized in the light of Flowers (1999) and the feature used to aid the organization of the categories was the Atlas ti software, showing two categories: Sustainability/Survivability and Organizational Management. It was observed that socializing capture experiences and resource mobilization can contribute to the advancement of support organizations. The dependence of funding is identified as a concern and a challenge for the survival of the OTS, for the lack of flexibility in mobilizing resources, creating insecurity for the implementation of projects of medium and long terms. The strategy that these organizations are seeking to decrease these problems is to strengthen the institution through new partnerships and network articulation to the development of public policies to meet the population's needs in terms of access to sports and also that meet the specificities of the sector.
\end{abstract}

Keywords: Strategy; Resource Management; Third Sector Organizations; Survival; Social Management

\section{Introdução}

Em geral, as organizações do terceiro setor (OTS), que promovem o empreendedorismo social com foco no esporte educacional e o de participação, desenvolvem projetos sociais em regiões pouco assistidas pelo Estado e com alto índice de vulnerabilidade social. A despeito da relevância social do serviço prestado, não raro, ainda hoje, muitas OTS se deparam com dificuldades para suas sobrevivências e, consequentemente, para a continuidade de seus projetos. Essas

MOTA, A. L. C.; NASSIF, V. M. J. Como sobreviver em um ambiente de financiamento instável? Gestão de recursos em organizações empreendedoras do terceiro setor que atuam com o esporte. Revista de Empreendedorismo e Gestão de Pequenas Empresas, v.5, n.1, 2016. 
questões configuram-se entre os principais desafios enfrentados pelos gestores de OTS no Brasil (PEREIRA et al., 2013).

O esporte no Brasil foi estruturado tendo como base as associações e clubes esportivos que se caracterizavam pelo acesso exclusivo a sócios e pelo foco competitivo. Não sócios eram admitidos apenas quando demonstravam potencial para o esporte de alto rendimento. Assim, instituiu-se uma base para o sistema esportivo nacional, reforçando o caráter elitista do esporte brasileiro (BUENO, 2008).

$\mathrm{Na}$ tentativa de minorar essa distorção, a Constituição Federal de 1988 estabeleceu que o acesso à prática de esporte, lazer e recreação é um dever do Estado e um direito do cidadão (BRASIL, 1988). Contudo, apesar da importância social, econômica e cultural, e também do grande interesse que desperta, o acesso à prática monitorada do esporte de forma regular e com qualidade ainda é restrito $\mathrm{e}$ parece se agravar com o aumento da idade das pessoas (ATLETAS PELO BRASIL, 2014).

Esse cenário acentua a relevância da atuação das Organizações Empreendedoras do Terceiro Setor (OETS) nesse campo e, por conseguinte, a importância de conhecer os desafios relacionados à sobrevivência dessas organizações.

Considerando os desafios relacionados às OETS que atuam com o esporte educacional e de participação no Brasil, e a carência de orientações específicas direcionadas para atender suas demandas, esta pesquisa teve por objetivo identificar quais são as estratégias relacionadas à gestão de recursos utilizadas pelas OETS que atuam com o esporte educacional e de participação visando à continuidade de seus projetos e sobrevivência. Os objetivos secundários foram: i) Analisar os fatores facilitadores relacionados às estratégias de gestão de recursos que influenciam a sobrevivência das OETS; e ii) Analisar os fatores críticos relacionados às estratégias de gestão de recursos que influenciam para a sobrevivência das OETS.

MOTA, A. L. C.; NASSIF, V. M. J. Como sobreviver em um ambiente de financiamento instável? Gestão de recursos em organizações empreendedoras do terceiro setor que atuam com o esporte. Revista de Empreendedorismo e Gestão de Pequenas Empresas, v.5, n.1, 2016. 


\section{Gestão em Organizações do Terceiro Setor}

Percebe-se que a busca da sobrevivência parece ser um dos fatores que levam as organizações a intensificar o processo de profissionalização e a procura por instrumentos e práticas de gestão para ampará-las em suas operações (SILVA, 2004). Quando as entidades não são autossustentadas, um dos desafios é conciliar suas funções de promoção da auto-organização social com as de caráter mais empresarial (BRESSER-PEREIRA; GRAU, 1999).

As organizações do terceiro setor (OTS) precisam desenvolver competências com o intuito de se fortalecerem na constituição de parcerias estratégicas. Entre elas, as que possibilitem construir articulações institucionais, necessárias para exporem suas gestões com transparência e produzirem serviços com padrão de qualidade, que gerem resultados efetivos e passíveis de avaliação pela sociedade (FISCHER, 2002).

Tanto as organizações filantrópicas tradicionais como as contemporâneas coexistem em um ambiente em que a sobrevivência organizacional passou a estar relacionada à adoção de práticas que permitam aferir seus níveis de eficiência, eficácia, efetividade e transparência (SILVA, 2004). Todavia, de acordo com Bresser-Pereira e Grau (1999), é necessário estabelecer critérios como base da avaliação que considere não só os critérios tradicionais, mas também os que atendam aos valores públicos.

A gestão social (GS) corresponde às organizações que atuam num âmbito que não é nem do Mercado nem do Estado, mas chamada sociedade civil - ou do TS -, portanto, uma esfera pública de ação que não é estatal. Essas organizações não visam objetivos econômicos como meio para a realização dos fins sociais. Essa inversão de prioridades em relação à lógica da empresa privada é o que condiciona a especificidade da GS (FRANÇA FILHO, 2008).

A ênfase do estudo da GS na visão de estudiosos é apresentada por Bordin (2013). A partir desse estudo foi possível identificar autores que destacam a GS como: gestão de estratégias e processos, visando à transformação da sociedade (DOWBOR, 2006); ou aqueles que respondam à questão social (MAIA, 2005); outros

MOTA, A. L. C.; NASSIF, V. M. J. Como sobreviver em um ambiente de financiamento instável? Gestão de recursos em organizações empreendedoras do terceiro setor que atuam com o esporte. Revista de Empreendedorismo e Gestão de Pequenas Empresas, v.5, n.1, 2016. 
como gestão das políticas sociais (SILVA, 2012; CARVALHO, 2007); ou como gestão de organizações (TENÓRIO, 2009; CARVALHO, 2007).

Empresas e OTS tornaram-se os principais atores da gestão social (GS), exigindo, na visão de Melo Neto e Froes (2001, p. 56), "contemporaneidade de políticas, novas ações, melhor gestão e profissionalismo na captação e alocação de recursos". Ao tentar definir algo que seria específico das OS, as expressões múltiplas da GS tendem a buscar uma particularidade, diferenciando-as assim da gestão pública governamental e da empresarial. Essas tentativas de construção do conceito de GS, compreender a sustentabilidade e sua eventual adaptação pelas organizações que praticam a GS é condição para pensar em instrumentos de gestão referentes à avaliação de projetos no monitoramento de suas atividades (MAGALHÃES et al., 2006).

Como metodologicamente a GS social refere-se a um conceito em construção, preocupações comuns relacionados às suas ações, como a conduta ética, a valorização da transparência na gestão dos recursos e a ênfase sobre a democratização das decisões e das relações na organização, apontam na direção de uma nova política que se dissemina por meio dessas práticas. Este aspecto constitui mais um desafio significativo que se coloca à GS (FRANÇA FILHO, 2008).

A gestão de OTS, à primeira vista, pode não exibir grandes diferenças de uma empresa privada. Ela ultrapassa os quatro pilares da administração, pois essas organizações convivem em um ambiente de natureza política e social que Ihes demanda mais do que o desenvolvimento e a entrega de um produto ou serviço, demanda a capacidade de equacionar aspectos empresariais, políticos e sociais (CARVALHO; FADUL, 2012).

Pereira et al. (2013) ressaltam a necessidade de uma análise mais criteriosa sobre as especificidades da gestão de OTS, entre elas as características, habilidades e competências individuais e coletivas necessárias para a gestão dessas organizações. Para esses autores, o planejamento nesse setor deve ser ainda mais participativo e democrático. Além disso, deve-se considerar fatores específicos para a análise do ambiente de acordo com quatro cenários: prestação de contas sobre a utilização de recursos (accountability), expansão de organizações lucrativas que

MOTA, A. L. C.; NASSIF, V. M. J. Como sobreviver em um ambiente de financiamento instável? Gestão de recursos em organizações empreendedoras do terceiro setor que atuam com o esporte. Revista de Empreendedorismo e Gestão de Pequenas Empresas, v.5, n.1, 2016. 
atuam em projetos sociais e ambientalmente sustentáveis, competição entre as entidades, o que dificulta as parcerias setoriais, e a necessidade de antever as tendências e desafios na área específica de atuação.

Esses autores apresentam também desafios inerentes à gestão no TS: gestão de pessoas, financeira, de projetos e mercadológica (PEREIRA et al., 2013). A existência desses fatores de diferenciação requer investigação para a identificação dos fatores de sucesso que potencializam ou dificultam o seu crescimento, sua evolução e sua relação com as fontes financiadoras (CARVALHO; FADUL, 2012).

A gestão de OTS deve adotar estratégias que viabilizem sua sustentabilidade não apenas financeira, mas política e social, ao longo do tempo (TENÓRIO, 2009). Corroborando essa visão, Magalhães et al. (2006) apontaram a sustentabilidade como preocupação central, ampliando a dimensão econômica e analisando outras dimensões de natureza política, social, cultural e ambiental.

Falconer (1999) entende a sustentabilidade como a capacidade permanente de obtenção de recursos financeiros, materiais ou humanos. Sachs (2000), por sua vez, propõe uma multidimensionalidade a partir das dimensões: social, cultural, ecológica, ambiental, territorial, econômica, política nacional e internacional.

É preciso notar ainda que a busca da sobrevivência parece ser um dos fatores que levaram as OTS a intensificarem o processo de profissionalização e a procurarem por instrumentos e práticas de gestão para ampará-las em suas operações (SILVA, 2010). Na medida em que não se tratam de entidades autossustentadas, um dos principais desafios é conciliar suas funções de promoção da auto-organização social com as de caráter mais empresarial (BRESSERPEREIRA; GRAU, 1999). Assim, as OTS têm sido desafiadas a se fortalecerem institucionalmente como condição à sua sobrevivência (ARMANI, 2003).

\section{Empreendedorismo Social (ES): Especificidades}

A capacidade que um empreendimento social tem de atender a dupla missão de criar valor social e ao mesmo tempo desenvolver um modelo de negócio

MOTA, A. L. C.; NASSIF, V. M. J. Como sobreviver em um ambiente de financiamento instável? Gestão de recursos em organizações empreendedoras do terceiro setor que atuam com o esporte. Revista de Empreendedorismo e Gestão de Pequenas Empresas, v.5, n.1, 2016 
financeiramente estável e autossustentável tem relação direta com o contexto em que opera (SHORT; MOSS; LUMPKIN, 2009).

O ambiente econômico e sociopolítico, a estrutura regulatória e a política fiscal, aspectos demográficos e socioculturais são exemplos de fatores contextuais que impactam no ES. Um contexto econômico adverso aumenta a demanda por serviços sociais ao mesmo tempo em que torna mais difícil obter doações ou investimentos (AUSTIN; STEVENSON; WEI-SKILLERN, 2006; MAIR, 2010; MAIR; MARTí, 2006).

É importante ressaltar que o contexto local molda as oportunidades e determina as estratégias e táticas a serem empregadas (MAIR, 2010). Isto porque o ES é resultado de um processo de interação contínua entre empreendedores sociais e o contexto no qual suas atividades estão inseridas. Essa visão denota que é impossível separar o agente - empreendedor social - da estrutura - comunidade, sociedade etc (MAIR; MARTí, 2006).

As OTS precisam considerar meios alternativos de apoio ou novos modos de criar riqueza social. As lições advindas do setor competitivo podem ser inestimáveis para a viabilização da sustentabilidade de empreendimentos sociais (ZAHRA et al., 2009). Profissionais do ES podem obter informações valiosas examinando lições do empreendedorismo convencional, tais como as relativas ao fracasso ou a compreensão dos processos de mobilização de recursos (DACIN; DACIN; MATEAR, 2010).

A mudança do modelo de relacionamento com os investidores internacionais, que passaram a atuar mais como assessores e consultores e menos como investidores, fez com que a diretriz passou a ser a eficiência e produtividade na gestão de recursos que garantissem a sobrevivência das próprias organizações e ter pessoal qualificado e competente para a elaboração de projetos sociais (GOHN, 1998, 2011).

O governo tem demonstrado ser incapaz de promover o social em todos os campos. Entidades filantrópicas buscam auxiliá-lo nessa missão, porém muitas vezes se mostram ineficazes, sem criatividade para superar obstáculos, como a carência de recursos financeiros, humanos e físicos. Surge assim, a oportunidade

MOTA, A. L. C.; NASSIF, V. M. J. Como sobreviver em um ambiente de financiamento instável? Gestão de recursos em organizações empreendedoras do terceiro setor que atuam com o esporte. Revista de Empreendedorismo e Gestão de Pequenas Empresas, v.5, n.1, 2016 
para os empreendedores sociais desenvolverem ideias inovadoras em busca de soluções empreendedoras para ampliar o valor social (BAGGENSTOSS; DONADONE, 2013).

Frente a essas reflexões, o presente artigo tem por objetivo identificar quais são as estratégias, relacionadas à gestão de recursos, utilizadas pelas OETS que atuam com o esporte educacional e de participação visando à continuidade de seus projetos e sua sobrevivência.

\section{Procedimentos Metodológicos}

Temas como esporte e estratégias relacionadas à gestão de recursos em OTS têm interessado pesquisadores, todavia, de forma isolada. Assim sendo, esta pesquisa buscou uma compreensão melhor acerca das estratégias utilizadas por organizações empreendedoras do terceiro setor (OETS) que atuam com o esporte educacional e de participação na gestão de recursos, visando sua sobrevivência e, por conseguinte, a continuidade de seus projetos.

$\mathrm{Na}$ pesquisa de ciências sociais aplicadas, os problemas surgem a partir de questões, dificuldades e práticas correntes (CRESWELL, 2007). As OETS se deparam com problemas relacionados à gestão em diferentes vertentes e aquelas que atuam com o esporte educacional e de participação, a literatura é incipiente, despertando a necessidade de averiguar as contribuições que estas duas proposições podem trazer (FALCONER, 1999).

Neste sentido, a questão básica que norteou esta pesquisa foi: Quais são as estratégias, relacionadas à gestão de recursos, utilizadas pelas OETS que atuam com o esporte educacional e de participação visando à continuidade de seus projetos e sua sobrevivência?

O estudo foi orientado pelos seguintes objetivos específicos: i) Analisar os fatores facilitadores relacionados às estratégias de gestão de recursos que influenciam a sobrevivência das OETS; e ii) Analisar os fatores críticos relacionados às estratégias de gestão de recursos que influenciam a sobrevivência das OETS.

MOTA, A. L. C.; NASSIF, V. M. J. Como sobreviver em um ambiente de financiamento instável? Gestão de recursos em organizações empreendedoras do terceiro setor que atuam com o esporte. Revista de Empreendedorismo e Gestão de Pequenas Empresas, v.5, n. 1,2016 
O método da pesquisa adotado foi o qualitativo e está baseado na perspectiva fenomenológica, visto que retrata a realidade a partir das experiências subjetivas dos participantes da pesquisa. A fenomenologia, segundo EasterbySmith, Thorpe e Lowe (1999), se preocupa em apreciar as diferentes construções e significados que as pessoas têm sobre sua experiência. Creswell (2007) complementa, evidenciando que tal abordagem inclui o estudo de problemas relacionados, ao adentrar o campo de percepção dos participantes, vendo como eles experimentam, vivem e expõem o fenômeno à procura de significados.

Nessa linha, o instrumento para a coleta de dados foi a entrevista apoiada em um roteiro semiestruturado, visando captar as ações realizadas que, segundo Martins e Theóphilo (2009), tem por finalidade, compreender o significado que entrevistados atribuem às questões e situações, em contextos que não foram estruturados anteriormente, com base nas suposições e conjecturas do pesquisador. As categorias que compuseram o roteiro semiestruturado (apresentadas mais a frente) foram: Sustentabilidade/Sobrevivência e Gestão Organizacional.

Inicialmente foi feito um levantamento de OETS que desenvolvem projetos com esporte educacional e de participação na região conhecida como Grande São Paulo. Em seguida, contatou-se os responsáveis para convidá-los a participarem das entrevistas. Após o acerto das agendas, foram realizadas onze entrevistas, com o fundador ou com o gestor, ou o diretor da organização. Das onze entrevistas, seis foram presenciais e as outras por meio do recurso tecnológico Skype. Todas as entrevistas foram gravadas com o consentimento dos participantes e tiveram duração de 1 h15 a 1h45. As entrevistas ocorreram entre agosto e dezembro de 2014.

As organizações que fizeram parte desta pesquisa autorizaram a divulgação de seus nomes, assim como de seus fundadores e entrevistados, conforme mostra o Quadro 1.

MOTA, A. L. C.; NASSIF, V. M. J. Como sobreviver em um ambiente de financiamento instável? Gestão de recursos em organizações empreendedoras do terceiro setor que atuam com o esporte. Revista de Empreendedorismo e Gestão de Pequenas Empresas, v.5, n.1, 2016. 
QUADRO 1- ORGANIZAÇÕES E RESPONDENTES DA PESQUISA.

\section{OETS PESQUISADAS}

\begin{tabular}{ll}
\hline Fundação EPROCAD & José Messias da Silva / Adolfo J. Vieira Pinto (E4) \\
\hline Fundação Gol de Letra & $\begin{array}{l}\text { Raí de Oliveira e Leonardo Nascimento de Araújo / Raí de } \\
\text { Oliveira (E9) e Sóstenes Brasileiro de Oliveira (E11) }\end{array}$ \\
\hline Instituto Barrichello-Kanaan & Rubens Barrichello e Tony Kanaan / William B. de Oliveira (E10) \\
\hline Instituto Compartilhar & $\begin{array}{l}\text { Bernardo Rocha de Rezende (Bernardinho) / Luiz Fernando A. } \\
\text { Nascimento (E6) }\end{array}$ \\
\hline Instituto Passe de Mágica & $\begin{array}{l}\text { Paula Gonçalves da Silva (Magic Paula) / Paula Gonçalves da } \\
\text { Silva (E1), Ismar B. Mendes (E2) e William B. de Oliveira (E3) }\end{array}$ \\
\hline Instituto Patrícia Medrado & $\begin{array}{l}\text { Patrícia Medrado / Patrícia Medrado (E7) e Osvaldo Camargo } \\
\text { Júnior (E8) }\end{array}$ \\
\hline ONG Futebol de Rua & Alceu de Campos Natal Neto / Alceu de Campos Natal Neto (E5) \\
\hline FONTE: As autoras (2016). &
\end{tabular}

Após a transcrição, os dados foram organizados em categorias de respostas à luz de Flores (1994), que assevera que a análise dos dados consiste em interpretar e analisar significados extraídos das entrevistas. Pata isto, utilizou-se o software Atlas ti.

A partir do referencial teórico, em especial, das proposições de Falconer (1999) e Armani (2003), e norteado pelo objetivo desta pesquisa, foram estabelecidas as seguintes categorias de respostas:

I) Sustentabilidade/Sobrevivência, que tem como conteúdo central: a capacidade de captar recursos e de utilizá-los com competência, de maneira a perpetuar a organização e permiti-la alcançar os seus objetivos; compatibilidade entre os tipos de receitas e de financiadores e suas "condicionalidades", relação entre financiamento institucional e por projeto;

II) Gestão Organizacional, que apresenta como conteúdo central: a gestão de recursos humanos.

\section{Categoria de Resposta I: Sustentabilidade/Sobrevivência}

No quadro 2 pode ser vista a categoria Sustentabilidade/Sobrevivência.

MOTA, A. L. C.; NASSIF, V. M. J. Como sobreviver em um ambiente de financiamento instável? Gestão de recursos em organizações empreendedoras do terceiro setor que atuam com o esporte. Revista de Empreendedorismo e Gestão de Pequenas Empresas, v.5, n. 1, 2016. 
QUADRO 2 - SUSTENTABILIDADE/SOBREVIVÊNCIA (S/S)

\begin{tabular}{|c|c|}
\hline Organização & Sustentabilidade/Sobrevivência \\
\hline A & $\begin{array}{l}\text { Captação de recursos } \\
\text { - Elabora e inscreve projetos nas leis de incentivo do esporte } \\
\text { - Não possui pessoa ou departamento que cuida especificamente da captação de } \\
\text { recursos } \\
\text { - Implantou ações voltadas para a captação de doações de pessoas físicas } \\
\text { - Não realiza ações específicas para atrair e fidelizar parceiros } \\
\text { Tipos de receitas/financiamentos } \\
\text { - Única fonte de recursos provém de recursos incentivados (indiretos) } \\
\text { - Parceiros diretos são apenas os que cedem espaços para a execução dos } \\
\text { projetos } \\
\text { Compatibilidade entre tipos de receitas/financiamentos e necessidades da } \\
\text { Organização } \\
\text { - Faltam recursos para gastos institucionais, para ter quadro de funcionários que } \\
\text { necessita e para comunicação e marketing } \\
\text { - Maior parte da receita vai para RH } \\
\text { - Restrições inerentes aos recursos incentivados dificultam sua mobilização } \\
\text { Principais desafios para a sobrevivência da Organização } \\
\text { - Mobilização de recursos de forma continuada e com recursos de verba direta } \\
\text { - Ida dos investidores para o esporte de alto rendimento } \\
\text { - Empresas substituíram o investimento direto pelo indireto (via dedução do } \\
\text { imposto devido) } \\
\text { - Empresas pulverizam os investimentos em várias Organizações } \\
\text { - Empresas estão montando seus próprios institutos } \\
\text { - Lei federal é mais dif́cil de captar (apenas empresas grandes) } \\
\text { - Lei estadual é menos clara em relação às glosas (quando o projeto não é } \\
\text { aprovado) } \\
\text { - Burocracia e falta de agilidade na liberação da verba incentivada compromete } \\
\text { continuidade dos proietos e expõe a Oraanizacão a riscos }\end{array}$ \\
\hline B & $\begin{array}{l}\text { Captação de recursos } \\
\text { - Elabora e inscreve projetos nas leis de incentivo do esporte e em editais } \\
\text { - Mantém convênio com o município onde está inserida } \\
\text { - Utiliza captador externo } \\
\text { - Tem parceria com uma organização internacional } \\
\text { - Realiza açães específicas para atrair e fidelizar parceiros } \\
\text { - Faz captação direta de pessoas físicas pelo site da Organização } \\
\text { Tipos de receitas/financiamentos } \\
\text { - Recebe financiamentos indiretos (via leis de incentivo) } \\
\text { - Recebe financiamentos diretos (prefeitura e organização internacional) } \\
\text { - Possui parceiro direto que fornece uniformes } \\
\text { Compatibilidade entre tipos de receitas/financiamentos e necessidades da } \\
\text { Organização } \\
\text { - Faltam recursos para investir na área de comunicação } \\
\text { - Maior parte da receita vai para RH } \\
\text { Principais desafios para a sobrevivência da Organização } \\
\text { - Legislação específica do setor não favorece } \\
\text { - Curta duração dos projetos } \\
\text { - Rotatividade de funcionários } \\
\text { - Atrair novos parceiros } \\
\text { - Conseguir mensurar resultados sociais } \\
\text { - "Mercado" competitivo } \\
\text { - Equipe reduzida e com pouca experiência (jovens) }\end{array}$ \\
\hline & $\begin{array}{l}\text { Captação de recursos } \\
\text { - Elabora e inscreve projetos nas leis de incentivo ao esporte } \\
\text { - Não possui departamento ou equipe exclusiva para captar recursos }\end{array}$ \\
\hline
\end{tabular}

MOTA, A. L. C.; NASSIF, V. M. J. Como sobreviver em um ambiente de financiamento instável? Gestão de recursos em organizações empreendedoras do terceiro setor que atuam com o esporte. Revista de Empreendedorismo e Gestão de Pequenas Empresas, v.5, n.1, 2016. 
C

- Utiliza captadores externos

- Realiza ações sistemáticas para atrair e fidelizar parceiros

Tipos de receitas/financiamentos

- Recebe financiamentos indiretos (via leis de incentivo)

- Possui parceiros pontuais que bancam materiais esportivos e pagamento de professor

- Recebe doações pontuais de empresas nacionais e de organizações internacionais

Compatibilidade entre tipos de receitas/financiamentos e necessidades da Organização

- Provisionamento de tudo que será gasto é feito com antecedência

- Maior parte dos recursos vai para RH

- Faltam recursos para questões institucionais e para formação e aperfeiçoamento da equipe

Principais desafios para a sobrevivência da Organização

- Captação de recursos de forma continuada

- Pouco envolvimento do poder público e atrair grandes empresas

- Legislação específica do setor não favorece

Captação de recursos

- Possui departamento/pessoa responsável, sendo que a maior parte dos recursos é captada diretamente com as empresas

- Apenas um financiador advém de leis de incentivo

- Imagem do fundador é utilizada para captar recursos diretos

- Realiza poucas ações para atrair e fidelizar parceiros

Tipos de receitas/financiamentos

- Recebe financiamentos diretos (verba das empresas)

- Recebe financiamento indireto (via leis de incentivo)

- Recebe investimentos para os projetos e também para questões institucionais

Compatibilidade entre tipos de receitas/financiamentos e necessidades da

D Organização

- Maior parte dos recursos vai para questões relacionadas aos projetos

- Gasto com RH é menor do que o da maioria das Organizações

- Tem flexibilidade para mobilizar os recursos

- Tem disponibilidade de recursos para questões institucionais, comunicação e eventos

- Equipe enxuta

Principais desafios para a sobrevivência da Organização

- Exigência de maior visibilidade dos parceiros

- Responsabilidade social x "intenções marqueteiras"

- Empresas estão migrando os financiamentos diretos para financiamentos via leis de incentivo

- Curta duração dos projetos: "projetos" x "programas"

Captação de recursos

- Inscreve projetos nas leis de incentivo do esporte

- Possui convênios com o poder público

- Não possui departamento ou equipe exclusiva para captar recursos

- Utiliza captadores externos

- Não realiza ações para atrair e fidelizar parceiros

E

Tipos de receitas/financiamentos

- Recebe apenas financiamentos indiretos (via leis de incentivo)

- Tem parceiro direto que cede espaço e com alguns consegue materiais esportivos

- Financiamentos são apenas nos projetos

Compatibilidade entre tipos de receitas/financiamentos e necessidades da

Organização

- Há necessidade de mais recursos para questões institucionais

- Morosidade na liberação de recursos incentivados compromete a execução dos

MOTA, A. L. C.; NASSIF, V. M. J. Como sobreviver em um ambiente de financiamento instável? Gestão de recursos em organizações empreendedoras do terceiro setor que atuam com o esporte. Revista de Empreendedorismo e Gestão de Pequenas Empresas, v.5, n.1, 2016. 
projetos

- Maior parte dos recursos vai para $\mathrm{RH}$

- Restrições inerentes aos recursos incentivados dificultam a manutenção da equipe

Principais desafios para a sobrevivência da Organização

- Projetos aprovados têm curta duração (um ano)

- Não ter financiamento para a Organização se manter (questões institucionais)

- Lei federal é mais difícil de captar (apenas empresas grandes)

- Conseguir captar recursos diretos para cobrir gastos institucionais

Captação de recursos

- Elabora e inscreve projetos nas leis de incentivo ao esporte e em editais

- Possui departamento próprio para captação de recursos articulado com a área de comunicação

- Utiliza também captadores externos

- Realiza ações específicas para atrair e fidelizar parceiros e doadores

- Faz captação direta de pessoas físicas e jurídicas pelo site da Organização

Tipos de receitas/financiamentos

- Recebe financiamento direto (verbas das empresas)

- Recebe financiamento indireto (via leis de incentivo)

- Possui prestadores de serviços e fornecedores de materiais pontuais

- Recebe financiamentos para os projetos e também para questões institucionais

Compatibilidade entre tipos de receitas/financiamentos e necessidades da

Organização

- Maior parte dos recursos vai para RH

- Assinala a necessidade de mais receitas para manter as equipes de captação de recursos e de comunicação e para gastos que estão além dos projetos

Principais desafios para a sobrevivência da Organização

- Dependência de lei de incentivo fiscal

- Modelo de financiamento no Brasil ainda está em construção e traz inseguranças para as OTS

- Arrefecimento da ajuda de organizações internacionais para o Brasil

Captação de recursos

- Elabora e inscreve projetos para as leis de incentivo do esporte

- Possui departamento para captar recursos e também utiliza captadores externos

- Tem parceria com agência de marketing

- Faz captação direta de pessoas físicas e jurídicas pelo site da Organização

- Não realiza ações sistemáticas para atrair e fidelizar parceiros

Tipos de receitas/financiamentos

- Recebe financiamento direto (dos próprios mantenedores) e indireto (via leis de incentivo)

- Recebe investimentos para os projetos e para questões institucionais

G

Compatibilidade entre tipos de receitas/financiamentos e necessidades da Organização

- Não identifica dificuldade significativa para conseguir investimentos para os projetos

- Maior parte dos recursos vai para $\mathrm{RH}$

- Faltam recursos para área de comunicação

- Aponta necessidade de mais investimento em pessoal da área financeira

Principais desafios para a sobrevivência da Organização

- Desenvolver projetos que tenham impacto e relevância

- Dar maior visibilidade e conseguir comunicar bem os resultados alcançados

- Manter aceso o relacionamento com os parceiros

- Ampliar o envolvimento direto do fundador na captação de recursos

FONTE: As autoras (2016)

MOTA, A. L. C.; NASSIF, V. M. J. Como sobreviver em um ambiente de financiamento instável? Gestão de recursos em organizações empreendedoras do terceiro setor que atuam com o esporte. Revista de Empreendedorismo e Gestão de Pequenas Empresas, v.5, n.1, 2016. 
Armani (2003) aponta o desafio representado pela busca de sustentabilidade/sobrevivência como basilar para as OTS. Nesse sentido, sugere que socializar experiências de captação e mobilização de recursos pode contribuir para o avanço da sustentação das organizações, via leis de incentivo. A dependência de financiamento é apontada pelos entrevistados como um desafio para a sobrevivência das OTS.

É sempre um risco criar uma dependência muito grande às leis de incentivo. (E9)

Estamos em um momento de reformular o estatuto para abrir esse leque e termos mais sustentabilidade. (E1)

Há um ano fizemos trabalho de planejamento estratégico e fomos entrevistar outras entidades [...] percebemos que ampliar a captação de recursos financeiros não é uma particularidade nossa. (E2)

Não queremos dependência de lei de incentivo [...] Temos um projeto não totalmente incentivado pra ter recurso direto e ter mais de flexibilidade. (E6)

As estratégias utilizadas pelas Organizações estão em conhecer formas alternativas utilizadas por outras organizações com maior know-how para captar recursos financeiros e buscar outras fontes de renda (doação direta de pessoa física). Os fatores críticos apontados são: terem dependência de leis de incentivo ao esporte para executar os projetos e não possuírem departamento para captação de recursos.

A preocupação com a dependência de financiamentos incentivados é justificada pelos entrevistados pela pouca flexibilidade na mobilização desse tipo de recurso, em especial, no que tange a custos institucionais (por exemplo, contas de água, luz, telefone, aluguel, etc.)

Os custos internos nem sempre são incentivados... acaba invadindo o recurso particular, privado... é uma preocupação que temos que ter. (E8) A verba da lei de incentivo não permite usar para comprar um copo de água, usar na divulgação etc. Tudo tem que estar dentro de uma planilha que é aprovada pelo Ministério. Eu tenho aluguel, correio, água, luz... E a gente tira da onde?! (E1)

A dependência de uma única fonte de recursos financeiros é um fator crítico, além de dificultar a continuidade dos projetos:

MOTA, A. L. C.; NASSIF, V. M. J. Como sobreviver em um ambiente de financiamento instável? Gestão de recursos em organizações empreendedoras do terceiro setor que atuam com o esporte. Revista de Empreendedorismo e Gestão de Pequenas Empresas, v.5, n.1, 2016. 
Existe uma dificuldade grande de captação pela lei federal, porque é imposto de renda, $1 \%$, aí só empresas grandes. (E2)

A lei federal permite um percentual para o captador, mas a estadual quer cortar... querem fazer um banco de empresas... Como a empresa vai escolher?! (E7)

As leis de incentivo ao esporte são as mesmas para o alto rendimento e para o social, olha que loucura! (E1)

Quanto à burocracia do poder público,

\begin{abstract}
Existe uma morosidade no repasse de verba. Então, é raro o projeto que você recebe antes que executa. (E7)

Ficamos na dependência da liberação dos recursos, da burocracia do governo para dar continuidade aos projetos. (E10)

Nós ficamos com um projeto três meses parado. Está lá, com o dinheiro captado, mas tem um documento que está rodando não sei onde e ninguém assina... (E1)
\end{abstract}

Em relação aos curtos prazos estabelecidos para a execução dos projetos aprovados, fica claro que:

\begin{abstract}
Quando fazemos parceria com uma empresa na Europa conseguimos parceria por três anos. No Brasil, por um ano. Então, dificulta qualquer tipo de planejamento! (E9)

Ter projeto de um ano frustra um pouco, porque você não tem continuidade... (E7)

[...] O projeto tem que ser de longo prazo pra gerar esse impacto de mudança no comportamento e na vida das crianças. (E6)

O que vai ser aprovado..., se vai ser aprovado...?! Essas questões provocaram discussão do planejamento estratégico, que é a sustentabilidade da Organização. (E2)

A maioria dos projetos é desenvolvida em doze meses. O que não permite fazer planejamento de médio ou longo prazo. (E4)
\end{abstract}

Esse contexto gera insegurança, instabilidade e dificuldades para a continuidade dos projetos, visando resultados em médio e longo prazos. A estratégia que essas Organizações vêm buscando para minorar esses problemas é o fortalecimento da instituição por meio de novas parcerias e da articulação em rede. O intuito é influenciar a construção de políticas públicas que contribuam para atender as necessidades da população no que tange ao acesso à prática de esportes e também que atendam as especificidades do setor.

Esses fatores impactam e desempenham um papel essencial sobre o empreendedorismo social, além de uma estreita relação com a capacidade para

MOTA, A. L. C.; NASSIF, V. M. J. Como sobreviver em um ambiente de financiamento instável? Gestão de recursos em organizações empreendedoras do terceiro setor que atuam com o esporte. Revista de Empreendedorismo e Gestão de Pequenas Empresas, v.5, n.1, 2016 
criar valor social e ao mesmo tempo desenvolver um negócio financeiramente estável (AUSTIN; STEVENSON; WEI-SKILLERN, 2006; KATZENSTEIN; CHRISPIN, 2011; MAIR, 2010; MAIR; MARTÍ, 2006; SHORT; MOSS; LUMPKIN, 2009).

Entre os principais fatores contextuais ressaltados, identificou-se a substituição, por parte das empresas, do investimento direto (via recursos de marketing) pelo indireto (via leis de incentivo), a pulverização desses investimentos entre várias organizações e a migração para o alto rendimento em busca de maior visibilidade e, por outro lado, o pouco espaço na mídia. Permeados a isso, também são citadas a cultura nacional do imediatismo, a insegurança advinda de um modelo de financiamento ainda em construção no Brasil, a falta de apoio do poder público e a criação de Fundações próprias pelas empresas.

Sustentar empreendimentos sociais requer forte orientação empreendedora alicerçada no uso de modelos estratégicos de negócio. No entanto, a aplicação desses modelos com práticas competitivas pode ser incoerente com os valores dos modelos sociais tradicionais (ZAHRA et al., 2009).

Como já se sabe, o empreendedorismo social é resultado de um processo de interação contínua entre empreendedores sociais e o contexto no qual suas atividades estão inseridas. Essa visão denota que é impossível separar o agente empreendedor social - da estrutura - comunidade, sociedade, etc (MAIR; MARTí, 2006).

Nas organizações, observou-se a importância ao financiamento direto como característica convergente atribuída por todos os entrevistados. Já em relação à divergente, constatou-se uma diferença quanto à representatividade desse tipo de financiamento na receita total de cada uma das organizações. Diretamente relacionada à escassez ou a ausência de financiamentos diretos está a carência de receita para investir em departamento de captação de recursos e, sobretudo, no de comunicação e marketing.

Corroborando os achados, Carvalho e Fadul (2012) asseveram que apesar das OTS guardarem semelhanças entre si, é notório a existência de fatores que as distinguem no aspecto econômico em relação: ao tamanho da estrutura e ao projeto, aos seus quadros técnicos, o volume de recursos que recebem e a visibilidade.

MOTA, A. L. C.; NASSIF, V. M. J. Como sobreviver em um ambiente de financiamento instável? Gestão de recursos em organizações empreendedoras do terceiro setor que atuam com o esporte. Revista de Empreendedorismo e Gestão de Pequenas Empresas, v.5, n.1, 2016. 
Desta forma, os autores propõem que a identificação dos fatores de sucesso na gestão e os que potencializam ou dificultam o seu crescimento, sua evolução e sua relação com as fontes financiadoras devem ser investigados.

Entre as estratégias apontadas pelos respondentes desta pesquisa como alternativas para lidar com a falta de recursos para as áreas de captação de recursos e de comunicação e marketing, tidas por todos como estratégicas, estão: conquistar voluntários de peso para esses setores, otimizar esses departamentos unificando suas equipes, enfatizar a causa e dar maior visibilidade aos projetos para atrair novos parceiros, especialmente financiadores diretos.

Algumas organizações realizam ações para atrair e fidelizar parceiros em eventos envolvendo os beneficiários dos projetos e os financiadores. Às vezes trazem funcionários para atuarem como voluntários em eventos especiais. Essas ações são importantes para apresentar o projeto, a organização e, sobretudo, a causa defendida aos parceiros. Assim, há maior envolvimento e fidelização desses financiadores.

\section{Categoria de resposta II: Gestão Organizacional}

\begin{tabular}{|c|c|}
\hline Organização & Gestão Organizacional \\
\hline A & $\begin{array}{l}\text { Gestão de recursos } \\
\text { - Pouca flexibilidade para a mobilização dos recursos captados } \\
\text { - Todos os funcionários são registrados (CLT) } \\
\text { - Quadro de funcionários é menor do que as necessidades da Organização } \\
\text { - Contratação de RH valoriza identificação com a causa social e história de vida } \\
\text { - Participação de voluntários ocorre apenas em ações pontuais } \\
\text { - Investe em atualização e formação continuadad dos funcionários } \\
\text { - Principais desafios na gestão de RH: pontualidade dos educadores }\end{array}$ \\
\hline B & $\begin{array}{l}\text { Gestão de recursos } \\
\text { - Pouca flexibilidade para a mobilização dos recursos captados } \\
\text { - Possui funcionários registrados (CLT), RPA, estagiários e terceirizados } \\
\text { - Tem parceria com poder público municipal para provimento de mão de obra } \\
\quad \text { específica } \\
\text { - Quadro de funcionários é menor do que as necessidades da Organização } \\
\text { - Contratação de RH valoriza identificação com a causa social } \\
\text { - Incentiva, mas não investe em atualização e formação continuada dos funcionários } \\
\text { - Principais desafios na gestão de RH: ter funcionários contratados por diferentes } \\
\text { modalidades }\end{array}$ \\
\hline C & $\begin{array}{l}\text { Gestão de recursos } \\
\text { - Todos os funcionários são registrados (CLT) } \\
\text { - Quadro de funcionários é menor do que as necessidades da Organização } \\
\text { - Contratação de } \mathrm{RH} \text { valoriza identificação com a causa social e história de vida }\end{array}$ \\
\hline
\end{tabular}

MOTA, A. L. C.; NASSIF, V. M. J. Como sobreviver em um ambiente de financiamento instável? Gestão de recursos em organizações empreendedoras do terceiro setor que atuam com o esporte. Revista de Empreendedorismo e Gestão de Pequenas Empresas, v.5, n.1, 2016. 
- Investe em atualização e formação continuada dos funcionários

- Conta com o apoio de agentes comunitários voluntários regulares

- Principais desafios na gestão de RH: relativa rotatividade dos educadores

Gestão de recursos

- Todos os funcionários são registrados (CLT)

- Educadores vêm de parceria com o poder público municipal

- Quadro de funcionários atende as necessidades da Organização

- Contratação de RH valoriza ex-alunos, identifica a causa social e experiência com

D esporte sem o viés do alto rendimento

- Não investe com regularidade em atualização e formação continuada dos

funcionários

- Participação de voluntários ocorre apenas esporadicamente

- Principais desafios na gestão de RH: avaliar e motivar mais os professores que são provenientes da parceria com o poder público

Gestão de recursos

- Pouca flexibilidade para a mobilização dos recursos captados

- Todos os funcionários são registrados (CLT)

- Alguns professores vêm do convênio com o poder público municipal

- Quadro de funcionários é menor do que as necessidades da Organização

E - Contratação de RH valoriza a identificação com a causa social

- Investe em atualização e formação continuada dos funcionários

- Participação de voluntários ocorre apenas esporadicamente

- Principais desafios na gestão de $\mathrm{RH}$ : arcar com custos trabalhistas não previstos no convênio que mantem com o poder público quando ocorrem quebra de contrato por mudança no governo

Gestão de recursos

- Todos os funcionários são registrados (CLT) e os monitores registrados como bolsistas

- Quadro de funcionários atende as necessidades da Organização

F $\quad$ - Contratação de RH valoriza a identificação com a causa social

- Investe em atualização e formação continuada dos funcionários

- Participação de voluntários ocorre apenas em situações pontuais

- Principais desafios na gestão de RH: comunicação interna e ter um profissional específico e com formação e experiência na área para cuidar desse setor

Gestão de recursos

- Tem funcionários registrados (CLT) e autônomos (RPA) e o quadro é menor do que a necessidade

G - Contratação de $\mathrm{RH}$ valoriza a identificação com a causa social

- Investe em atualização e formação continuada dos funcionários

- Participação de voluntários ocorre em situações pontuais

- Principais desafios na gestão de RH: apesar de ter que renovar contratos anualmente, profissionais se mantém devido à identificação com os projetos e a valorização profissional

FONTE: As autoras (2016).

Os principais aspectos evidenciados no que tange à $\mathrm{GO}$, especificamente aqueles relacionados à gestão de recursos humanos $(\mathrm{GRH})$, demonstram que ela é vista como um fator muito importante para o desenvolvimento e execução dos projetos. A busca por profissionais qualificados e identificados com a causa social é um desafio. Os gastos com $\mathrm{RH}$ são tidos como investimento. Todavia, os altos custos trabalhistas também são apontados como entraves na gestão da

MOTA, A. L. C.; NASSIF, V. M. J. Como sobreviver em um ambiente de financiamento instável? Gestão de recursos em organizações empreendedoras do terceiro setor que atuam com o esporte. Revista de Empreendedorismo e Gestão de Pequenas Empresas, v.5, n.1, 2016. 
organização.

O perfil dos funcionários que as organizações buscam é revelado a seguir:

[...] A gente busca um profissional sensível para as questões sociais e também valorizamos proatividade, agilidade, liderança. [...] Todos têm, no mínimo, formação superior, no entanto, em relação à quantidade, estamos longe do ideal por causa das adequações financeiras. (E3)

Valorizamos um perfil mais humano, gostar de criança, gostar de trabalho social comunitário, se doar muito. Optamos por aquelas pessoas que se identificam com o perfil da instituição e o perfil do projeto. (E4)

[...] A gente busca nessa seleção é o viés social. Tem que gostar de lidar com pessoas menos favorecidas. (E7)

Tem que ter identificação com a causa social, com as questões sociais e também com o público. Precisa ser formado e ter a capacidade de escuta... trazer pessoas que tenham sensibilidade para entender de gente. (E10)

A percepção sobre os gastos/investimentos com $\mathrm{RH}$ são apontadas da seguinte maneira:

O gasto com $\mathrm{RH}$ está muito próximo de $60 \%$ de tudo que é investido. Quando o projeto contempla a contratação por CLT, com os encargos trabalhistas, pode ser até mais. Se eu não tiver bons profissionais a minha entrega final não vai ser boa. Eu prefiro remunerar bem, de acordo com o que é praticado no Mercado. (E4)

A maior parte da nossa receita vai para o $\mathrm{RH}$, devido aos custos trabalhistas [...] Todos são registrados CLT e isso quase triplica o custo do projeto. (E2) No nosso planejamento estratégico decidimos que não trabalharíamos correndo riscos. São todos registrados (E1).

Identificou-se uma exceção entre as organizações quanto aos gastos em

$\mathrm{RH}$ :

Normalmente o RH envolveria cerca de $70 \%$ de custo de uma entidade, de um projeto. No nosso caso, o projeto não tem muito $\mathrm{RH}$, a gente consegue manter com um custo muito barato. (E6)

Afora os custos trabalhistas elevados - comuns a qualquer organização, seja ela do TS ou não, pois a legislação é a mesma - e a quase unanimidade quanto à existência de um quadro de funcionários qualificado, porém, em número menor do que consideram como ideal, foram assinaladas dificuldades pontuais em algumas organizações em relação à $\mathrm{GRH}$. Por exemplo, a contratação de funcionários por modalidades distintas (CLT - registrado ou RPA - autônomo) e a rotatividade

MOTA, A. L. C.; NASSIF, V. M. J. Como sobreviver em um ambiente de financiamento instável? Gestão de recursos em organizações empreendedoras do terceiro setor que atuam com o esporte. Revista de Empreendedorismo e Gestão de Pequenas Empresas, v.5, n.1, 2016. 
destes; a dificuldade de avaliar os professores e conseguir motivá-los ao longo do tempo quando advêm da parceria com o poder público; falha na comunicação interna e ausência de formação e experiência em gestão de $\mathrm{RH}$.

Para minorar esses gastos, a principal estratégia identificada é selecionar funcionários engajados. Assim, além de favorecer o desenvolvimento dos projetos, essa estratégia contribui para diminuir a rotatividade. Outra forma foi buscar parcerias com o poder público para prover funcionários, reduzindo o gasto com a folha de pagamento.

De acordo com Falconer (1999), há carência de $\mathrm{RH}$ capacitados implicando em uma baixa capacidade de sustentabilidade das OTS. Por sua vez, Pereira et al. (2013) associaram, entre os desafios inerentes à $\mathrm{GRH}$, o envolvimento de todos com a missão organizacional. Todavia, no contexto das organizações pesquisadas, foram obtidos resultados diferentes, cujas estratégias se voltam para a contratação de funcionários que tenham afinidade como a causa social e também com o investimento em suas formações continuada. Esse resultado contraria o que foi encontrado na literatura, notadamente por se tratar de um contexto no qual a duração dos projetos é curta.

As organizações apresentam características e formas de atuações distintas quanto à gestão de recursos financeiros e humanos. Entre as estratégias evidenciadas na pesquisa que contribuem para sobrevivência das organizações estão: o foco no desenvolvimento de projetos que tenham impacto e relevância social, a valorização do planejamento participativo e a sistematização do trabalho desenvolvido.

Por outro lado, para algumas delas, a dificuldade para fazer regularmente 0 planejamento estratégico e executar o que foi estabelecido aparecem como fatores críticos. Outro aspecto crítico citado é a mensuração de resultados sociais de forma concreta, que possibilite uma comunicação clara dos resultados aos stakeholders e também favoreça a vinda de novos parceiros e a captação de recursos.

Para Mair (2010), a missão do empreendedorismo social é efetuar a mudança, alterando as realidades sociais, econômicas e políticas em nível local. Assim, é o contexto local que molda as oportunidades e determina as estratégias e

MOTA, A. L. C.; NASSIF, V. M. J. Como sobreviver em um ambiente de financiamento instável? Gestão de recursos em organizações empreendedoras do terceiro setor que atuam com o esporte. Revista de Empreendedorismo e Gestão de Pequenas Empresas, v.5, n.1, 2016. 
as táticas a serem empregadas. O contexto diversificado em que operam as OETS no Brasil explicam as estratégias distintas utilizadas pelas organizações pesquisadas neste estudo no que tange à sua gestão.

Nessa esteira, Pereira et al. (2013) ressaltam a necessidade de uma análise criteriosa sobre as especificidades da gestão de OTS e assinalam que o planejamento nesse setor deve ser ainda mais participativo e democrático, aspecto evidenciado nas organizações pesquisadas. Mair e Martí (2006) sugerem que, em vez de se concentrar no sucesso ou fracasso de uma iniciativa de empreendedorismo social, seria melhor medir "graus" de sucesso ou fracasso, tendo em mente as consequências intencionais e não intencionais da iniciativa.

Por fim, Zahra et al. (2009) explica que a delimitação de um padrão de riqueza econômica e social pode ser útil para acadêmicos, doadores e empreendedores, e também fornecer um ponto de referência para a avaliação do desempenho de empreendimentos sociais. A partir dele, os empreendedores poderiam se concentrar em alcançar melhores resultados e os doadores em monitorá-los.

\section{Considerações Finais}

Antes de tudo, é preciso dizer que pesquisar sobre as estratégias relacionadas à gestão de recursos utilizadas pelas organizações empreendedoras do terceiro setor (OETS) que atuam com o esporte educacional e de participação visando a continuidade de seus projetos e sua sobrevivência é um desafio, considerando que este tipo de pesquisa, especialmente no Brasil, ainda é incipiente.

Nesse sentido, considera-se importante o aprofundamento desses estudos, dada a relevância social e política dessas organizações para minorar problemas sociais ainda prementes na sociedade brasileira, tais como a exclusão social, a baixa qualidade da educação, a falta de acesso à prática de esportes para todos, conforme garantidos na Constituição Federal do Brasil de 1988.

MOTA, A. L. C.; NASSIF, V. M. J. Como sobreviver em um ambiente de financiamento instável? Gestão de recursos em organizações empreendedoras do terceiro setor que atuam com o esporte. Revista de Empreendedorismo e Gestão de Pequenas Empresas, v.5, n.1, 2016. 
As OETS fazem parte do sistema social, político e econômico do País. Prestam serviços em setores nos quais o poder público não consegue - ou muitas vezes não se interessam - atender. Suprem, portanto, uma lacuna deixada pelo Estado, mas mais do que isso, realizam um trabalho importante para a construção de uma sociedade mais justa socialmente. Mesmo contanto com uma lei específica - Marco Regulatório do Terceiro Setor - a adequação desta às necessidades do setor, apesar dos avanços observados, ainda não se dá de maneira satisfatória. Com isso, essas organizações se deparam muitas vezes com dificuldades que podem comprometer o desenvolvimento e a continuidade de seus projetos e até mesmo inviabilizar a sua sobrevivência.

Ao pesquisar aspectos relacionados à gestão de recursos financeiros e humanos dessas OETS, observou-se é possível minorar desafios se a gestão focar em estratégias criativas e inovadoras para superar fatores críticos para sua sobrevivência, como a burocracia do poder público, as restrições inerentes às leis de incentivo, o modelo de financiamento ainda em construção no Brasil que traz inseguranças para as organizações, a curta duração dos projetos e os altos custos trabalhistas.

Olhar os custos com a gestão de recursos humanos como investimentos, sobretudo, no que diz respeito à contratação de funcionários qualificados e identificados com a causa social, bem como em formação continuada, são estratégias relevantes para a continuidade dos projetos que as OETS desenvolvem. Investir em planejamento participativo, no desenvolvimento de projetos que tenham impacto e relevância social, assim como estabelecer parcerias e buscar articulação política com outras organizações são estratégias que favorecem o fortalecimento institucional e também do setor como um todo. Por conseguinte, contribuem para a sobrevivência dessas organizações.

Importante salientar que a presente pesquisa não é um fim em si mesmo. Apesar de seus resultados propiciarem respostas para a questão de pesquisa e também para os objetivos delineados, eles não podem ser generalizados. As contribuições desveladas circunstanciam as OETS que atuam com esporte educacional e de participação respondentes da presente pesquisa. No entanto, dada

MOTA, A. L. C.; NASSIF, V. M. J. Como sobreviver em um ambiente de financiamento instável? Gestão de recursos em organizações empreendedoras do terceiro setor que atuam com o esporte. Revista de Empreendedorismo e Gestão de Pequenas Empresas, v.5, n.1, 2016. 
a profundidade com que os dados foram tratados, outras organizações com similaridades de atuação podem usufruir com a troca de aprendizagem expressa pelos empreendedores sociais que participaram da pesquisa.

Outro ponto a ser considerado trata-se da literatura incipiente sobre o tema estudado, dificultando a comparação dos resultados com outras OETS de outras regiões. Por outro lado, considerando a maturidade adquirida neste processo de pesquisa, sugere-se algumas alternativas para trabalhos futuros: aprofundar os estudos de cada um dos fatores abordados na pesquisa que influenciam a sobrevivências de OETS que atuam em diferentes setores e investigar a importância de atuação em rede para fortalecer o setor, visando à conquista de mudanças das políticas públicas para favorecer a sociedade, de forma mais ampla, e as OETS, em particular.

\section{Referências:}

ARMANI, D. O Desenvolvimento Institucional como condição de sustentabilidade das ONGs no Brasil. In: CÂMARA, C. (Org.) Aids e Sustentabilidade: sobre as ações das Organizações da Sociedade Civil. Brasília: Ministério da Saúde, 2003.

ATLETAS PELO BRASIL. I Relatório Cidades do Esporte. 1. ed., novembro, 2014.

AUSTIN, J.; STEVENSON, H.; WEI-SKILLERN, J. Social and commercial entrepreneurship: Same, different, or both? Entrepreneurship Theory and Practice, v.30, n. 1, p.1-22, 2006.

BAGGENSTOSS, S.; DONADONE, J. C. Empreendedorismo social: reflexões acerca do papel das organizações e do Estado. Gestão e Sociedade, v. 7, n. 16, p. 112-131, 2013.

BORDIN, E. M. B. A Gestão Social no contexto das Organizações da Sociedade Civil: desafios para efetivação da cidadania. Cadernos Gestão Social, v. 4, n. 1, p. 39-56, 2013.

BRASIL. Constituição Federal brasileira. São Paulo: Tecnoprint, 1988.

BRESSER-PEREIRA, L. C.; GRAU, N. C. (Orgs.). O público não-estatal na reforma do Estado. Rio de Janeiro: Fundação Getúlio Vargas, 1999.

BUENO, L. Políticas públicas do esporte no Brasil: razões para o predomínio do alto rendimento. 2008. 200 f. Tese (Doutorado em Administração Pública e

MOTA, A. L. C.; NASSIF, V. M. J. Como sobreviver em um ambiente de financiamento instável? Gestão de recursos em organizações empreendedoras do terceiro setor que atuam com o esporte. Revista de Empreendedorismo e Gestão de Pequenas Empresas, v.5, n.1, 2016. 
Governo). Escola de Administração de Empresas da Fundação Getúlio Vargas, São Paulo, 2008.

CARVALHO, A. O.; FADUL, E. M. C. Os Fatores Críticos de Sucesso na Gestão de Organizações Não Governamentais. APGS, v. 4, n. 2, p. 148-171, 2012.

CARVALHO, M. C. B. A ação em rede na implementação de políticas e programas sociais públicos. Disponível em: <http://www.cenpec.org.br/modules/ xt_conteudo/index.php?id=31 >. Acesso em: 05 jul. 2007.

CRESWELL, J. W. Projeto de Pesquisa: métodos qualitativo, quantitativo e misto. Porto Alegre: Artmed, 2007.

DACIN, P. A.; DACIN, M. T.; MATEAR, M. Social entrepreneurship: Why we don't need a new theory and how we move forward from here. Academy of Management Perspectives, v. 24, n. 3, p. 37-57, 2010.

DOWBOR, L. Gestão social e transformação da sociedade. 2006. Disponível em: <http:www.dowbor.org >. Acesso em: 17 set. 2006.

EASTERBY-SMITH, M.; THORPE, R.; LOWE, A. Pesquisa gerencial em administração. São Paulo: Pioneira, 1999.

FALCONER, A. P. A Promessa do Terceiro Setor: um estudo sobre a construção do papel das Organizações Sem Fins Lucrativos e do seu campo de gestão. São Paulo: CEATS/USP, 1999.

FISCHER, R. M.. A constituição dos três setores no Brasil. In: __. O desafio da colaboração: práticas de responsabilidade social entre empresa e Terceiro Setor. São Paulo: Gente, 2002.

FLORES, J. G. Análisis de datos cualitativos: aplicaciones a la investigación educativa. Barcelona: LTC, PPU S.A, 1994.

FRANÇA FILHO, G. C. Definindo gestão social. In: SILVA JR et al. (Orgs.): Gestão Social: Práticas em Debate, Teorias em Construção. Universidade Federal do Ceará, 2008.

GOHN, M. G. Movimentos sociais na contemporaneidade. Revista Brasileira de Educação, v. 16, n. 47, p. 333-361, 2011.

GOHN, M. G. O Novo Associativismo e o Terceiro Setor. Revista Serviço Social e Sociedade, v. 19, n. 58, p. 9-23, 1998.

KATZENSTEIN, J.; CHRISPIN, B. R. Social Entrepreneurship and a New Model For International Development In The 21st Century. Journal of Developmental Entrepreneurship, v. 16, n. 1, p. 87-102, 2011.

MOTA, A. L. C.; NASSIF, V. M. J. Como sobreviver em um ambiente de financiamento instável? Gestão de recursos em organizações empreendedoras do terceiro setor que atuam com o esporte. Revista de Empreendedorismo e Gestão de Pequenas Empresas, v.5, n.1, 2016. 
MAGALHÃES, O. A. V. et al. (Re) Definindo a sustentabilidade no complexo contexto da gestão social: reflexões a partir de dias práticas sociais. Cadernos EBAPE.BR, v. 4, n. 2, p. 1-17, 2006.

MAIA, M. Gestão Social - Reconhecendo e construindo referenciais. Revista Virtual Textos \& Contextos, n.4, dez. 2005

MAIR, J. Social Entrepreneurship: taking stock and looking ahead. IESE Business School - University of Navarra, WP n. 888, Nov. 2010.

MAIR, J.; MARTÍ, I. Social entrepreneurship research: a source of explanation, prediction, and delight. J. World Business, v. 41, n. 1, p. 36-44, 2006.

MARTINS, G. A.; THEÓPHILO, C. R. Metodologia da investigação científica para ciências sociais aplicadas. 2. ed. São Paulo: Atlas, 2009.

MELO NETO, F. P.; FROES, C. Gestão da responsabilidade social corporativa: o caso brasileiro. Rio de Janeiro: Qualitymark, 2001.

PEREIRA, R. S.; MORAES, F. C. C.; MATTOS JUNIOR, A. B.; PALMISANO, A. Especificidades da Gestão no Terceiro Setor. Revista Organizações em Contexto, v. 9, n. 18, p. 167-195, 2013.

SACHS, I. Sociedade, Cultura e Meio Ambiente. Mundo \& Vida, v.2, n.1, 2000.

SHORT, J. C.; MOSS, T. W.; LUMPKIN, G.T. Research in social entrepreneurship: Past contribution and future opportunities. Strategic Entrepreneurship Journal, v. 3, n. 2, p.161-194, 2009.

SILVA, A. A. A gestão da seguridade social brasileira: entre a política pública e o mercado. São Paulo: Cortez, 2004.

SILVA, A. C. A. Trajetórias de classe e empreendedorismo social: um estudo exploratório. Tese de Mestrado em Intervenção Social, Inovação e Empreendedorismo, Faculdade de Economia e à Faculdade de Psicologia e de Ciências da Educação. Universidade de Coimbra, 2012.

SILVA, C. G. E. Gestão, legislação e fontes de recursos no terceiro setor brasileiro: uma perspectiva histórica. RAP, v. 44, n. 6, p. 1301-1325, 2010.

TENÓRIO, F. G. Gestão de ONGs: principais funções gerenciais. 11. ed. Rio de Janeiro: Editora FGV, 2009.

ZAHRA, S. A. et al. Atypology of social entrepreneurs: Motives, search processes and ethical challenges. Journal of Business Venturing, v. 24, n. 5, p. 519-532, 2009.

MOTA, A. L. C.; NASSIF, V. M. J. Como sobreviver em um ambiente de financiamento instável? Gestão de recursos em organizações empreendedoras do terceiro setor que atuam com o esporte. Revista de Empreendedorismo e Gestão de Pequenas Empresas, v.5, n.1, 2016. 